\title{
CRESCIMENTO INICIAL DO MILHO SOB DIFERENTES CONCENTRAÇÕES DE BIOFERTILIZANTE BOVINO
}

\author{
Initial corn growth under different (bovine) biofertilizer dosages \\ MARIO DE OLIVEIRA REBOUÇAS NETO ${ }^{1}$ \\ DREYCIELLE NUNES PEREIRA LEITE ${ }^{2}$ \\ JANÁIRA ROCHA CAMPOS² \\ CAROLINE LEITE VERAS ${ }^{2}$ \\ IANIANE RIBEIRO DE SOUZA² \\ LUIS RODRIGUES MONTEIRO FILHO ${ }^{2}$
}

\begin{abstract}
RESUMO: O objetivo deste trabalho foi avaliar o crescimento inicial de plantas de milho em solo adubado com diferentes concentrações de biofertilizante bovino. O experimento foi conduzido em ambiente telado do Centro Vocacional Tecnologia em produção Orgânica (CVT) localizado no Instituto Federal do Piauí-IFPI, Campus Campo Maior. O plantio das sementes deu-se em vasos com capacidade de $12 \mathrm{~kg}$, contendo como substrato areia + esterco caprino na proporção 3:1. O experimento obedeceu a um delineamento em blocos casualizados com 5 tratamento, referentes a cinco concentrações de biofertilizante: $\mathrm{C} 1=25 \%$ bio $+75 \%$ água, C2 $=$ $50 \%$ bio +50 água ), C3 $=75 \%$ bio $+25 \%$ água, C4 $=100 \%$ bio e C $5=124 \%$ bio e quatro repetições. Foram analisadas o crescimento inicial das plantas utilizando-se as seguintes características: altura de plantas, diâmetro do colmo, área foliar, matéria seca da parte aérea, da raiz e matéria seca total. $\mathrm{O}$ incremento nas doses de fertilizante orgânico bovino proporcionou aumento da MSR, MSPA e MST. Para a variável área foliar a concentração que promoveu um maior desenvolvimento foi a dose de $73,7 \%$ de biofertilizante.
\end{abstract}

Palavras-chave: Zea mays L. Desenvolvimento. Insumo orgânico.

\begin{abstract}
This work evaluates the initial growth of corn plants in soil treated with different dosages of bovine biofertilizer (in a substrate containing goat manure). The experiment was conducted in controlled environment on the grounds of the Centro Vocacional de Tecnologia em produção Orgânica (CVT) located at the Instituto Federal do Piauí-IFPI, Campus Campo Maior. The seeds were planted in pots with capacity for $12 \mathrm{~kg}$, containing 3:1 sand+goat manure as substrate. The experiment was set up in randomized blocks with five treatments and four replications. The treatments corresponded to five biofertilizer dosages (taken relatively to 100\% standard pure biofertilizer dosage). The treatments were: $\mathrm{C} 1=25 \%$ standard dosage in biofertilizer $+75 \%$ standard dosage in water, C2 $=50 \%$ standard dosage in biofertilizer +50 standard dosage in water), C3 $=75 \%$ standard dosage in biofertilizer $+25 \%$ standard dosage in water, C4 $=100 \%$ standard dosage in biofertilizer and C5 $=124 \%$ standard dosage in biofertilizer. The initial plant growth was analyzed through the following characteristics: plant height, stem diameter, leaf area (LA), dry mass of the aerial parts (DMAP), root dry mass (RDM) and total dry mass (TDM). The increment in organic bovine fertilizer dosage corresponded to an increment in RDM , DMAP and TDM. The Leaf Area was most enhanced by a biofertilizer dosage of $73.7 \%$ (of the standard biofertilizer dosage).
\end{abstract}

Keywords: Zea mays L. Development. organic input.

\footnotetext{
${ }^{1}$ Doutor em Irrigação e Drenagem. Professor de Agricultura do IFPI.

2 Graduandos em agricultura no IFPI.
} 


\section{INTRODUÇÃO}

O milho (Zea mays L.) originário da América Central e cultivado em todo o Brasil tem grande importância econômica, devido às diversas formas de sua utilização, desde a alimentação humana e animal até a indústria de alta tecnologia e utilização na produção de biocombustíveis (FORNASIERI FILHO, 2007).

A importância econômica do milho é caracterizada pelas diversas formas de sua utilização. Na realidade, o uso do milho em grão como alimentação animal representa maior parte do consumo desse cereal, ou seja, cerca de $70 \%$ no mundo. A importância do milho ainda está relacionada ao aspecto social, pois grande parte dos produtores não é altamente tecnificada (BEZERRA et al., 2008).

Severino et al. (2004) afirmam que fertilizantes sintéticos quando disponibilizados no solo, podem ser perdidos boa parte por lixiviação, volatilização ou fixação. Já os adubos orgânicos são liberados de forma gradual disponibilizando os nutrientes por mais tempo no solo para suprir as necessidades dos vegetais.

Se comparado com o fertilizante químico, o biofertilizante apresenta algumas vantagens, como por exemplo: favorece a multiplicação de microrganismos benéficos, que por sua vez propiciam mais vida e saúde ao solo; tornam o solo mais poroso, permitindo maior aeração em camadas mais profundas, propiciando um maior desenvolvimento das plantas (IZUMI et. al., 2010).

A cultura do milho responde bem à adubação orgânica, sendo aumentada a sua produtividade quando o solo é adubado com estercos de animais, compostos orgânicos, húmus de minhoca e biofertilizantes (SANTOS, 1992). Os biofertilizantes estão surgindo como alternativas para os pequenos produtores rurais, pois representam redução de custos, são acessíveis ás condições técnico-econômicas deles, bem como atendem a preocupação com a qualidade de vida no planeta (BEZERRA et al. 2008).

O biofertilizante bovino na forma líquida apresenta na sua composição microrganismos responsáveis pela decomposição da matéria orgânica, produção de sais e adição de compostos orgânicos e inorgânicos que atuam não só na planta, mas também, sobre a atividade microbiana do solo (BETTTIOL et al., 1998).

Maghanaki et. al. (2013) explicam que o biofertilizante líquido é absorvido com maior facilidade pelo solo do que o sólido, pois este penetra diretamente na raiz da planta, sendo que o sólido necessita de água da chuva ou irrigação para dissolver-se e fornecer os nutrientes necessários à planta.

De acordo com Cavalcante et al. (2010) além dos efeitos promovidos na estruturação física do solo, o esterco bovino líquido aplicado na superfície do substrato forma uma camada de 
impedimento às perdas elevadas de água por evaporação, o que possibilita às células vegetais permanecerem túrgidas por mais tempo em relação às plantas que não receberam o insumo.

Diversos trabalhos tem sido desenvolvidos por diferentes pesquisadores quanto ao uso do biofertilizante como Oliveira et al. (2014) que encontraram resposta positiva ao uso de biofertilizante pela cultura do maxixeiro. Outros trabalhos com resultados semelhantes ao uso de biofertilizante têm sido observados por outros autores para outras hortaliças, tais como: tomate (GOMES JÚNIOR et al., 2011), abóbora (SANTOS et al., 2012) e meloeiro (SANTOS et al., 2014).. Esses resultados positivos ocorrem em razão do efeito do biofertilizante sobre a fisiologia das plantas, elevando as taxas de fotossíntese, transpiração e a condutância estomática, bem como na nutrição mineral das plantas (ERTHAL et al., 2010;SILVA et al., 2011;VIANA et al., 2013).

Diante desse contexto, o objetivo deste trabalho foi avaliar o crescimento inicial de plantas de milho em solo adubado com diferentes concentrações de biofertilizante bovino.

\section{MATERIAL E MÉTODOS}

O experimento foi conduzido em ambiente protegido do na área experimental do Centro Vocacional Tecnológico em produção Orgânica e Agroecológica (CVT) no IFPI-Campus Campo Maior, localizado em Campo Maior-PI (4 44'S latitude, 43 33’W longitude e $137 \mathrm{~m}$ de altitude). Segundo a classificação de Koppen, o clima da região é classificado como do tipo Aw, quente e úmido com chuvas de verão e outono, sendo que a estação chuvosa dessa região ocorre de janeiro a maio, destacando-se fevereiro, março e abril como trimestre com maior índice pluviométrico e agosto, setembro e outubro o mais seco. A média pluviométrica anual varia entre $1.000 \mathrm{~mm}$ a $1.800 \mathrm{~mm}$. O solo utilizado como substrato é classificado como latossolo vermelho amarelo (EMBRAPA, 2006). Foram coletadas amostras compostas na camada de 0-20 cm de profundidade e submetidas às análises laboratoriais para determinação dos atributos físicos e químicos, indicados na Tabela 1, conforme Embrapa (1997) e Richards (1954).

Tabela 1. Atríbutos químicos do solo antes da aplicação dos tratamentos.

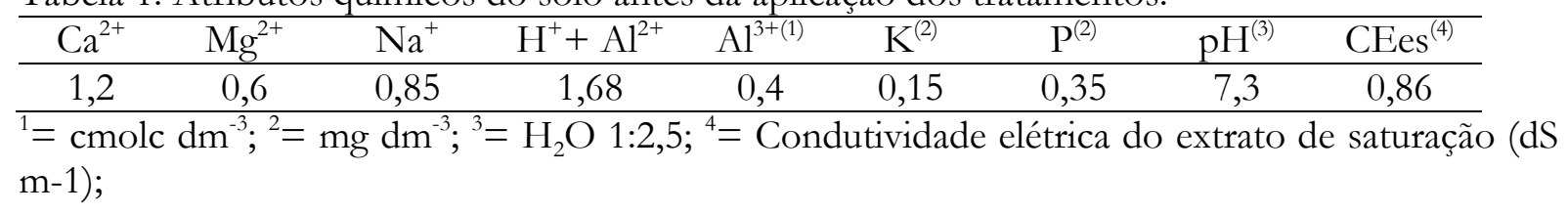

O plantio das sementes de milho crioulo foi feito em vasos plásticos com capacidade de $12 \mathrm{~kg}$, e realizado em junho de 2016. Após o estabelecimento das plântulas, aos cinco dias depois da semeadura (DAS), fez-se o desbaste deixando-se uma planta por vaso. O delineamento 
experimental foi de blocos ao acaso, com quatro repetições. Os tratamentos foram constituídos de cinco concentrações de biofertilizante ( $\mathrm{C} 1=25 \%$ bio $+75 \%$ água (1:3), $\mathrm{C} 2=50 \%$ bio +50 água (1:1), C3 $=75 \%$ bio $+25 \%$ água (3:1), C4 $=100 \%$ bio e C5 $=124 \%$ bio.) diluídas em água não salina, aplicadas em cada vaso em volume correspondente a $10 \%$ do volume do substrato $\left(1,2 \mathrm{~L}_{\text {planta }}{ }^{-1}\right)$ irrigada com água de média salinidade $\left(3,1 \mathrm{dS} \mathrm{m}^{-1}\right)$

O Biofertlizante utilizado foi produzido a partir de $70 \mathrm{~kg}$ de esterco fresco bovino e 120 litros de água, adicionando-se, também, $5 \mathrm{~kg}$ de rapadura e 5 litros de leite para acelerar o metabolismo das bactérias, sendo produzidos de forma anaeróbia. Para se obter o sistema anaeróbio, a mistura foi colocada em uma bombona plástica de $200 \mathrm{~L}$ deixando-se um espaço vazio de 15 a $20 \mathrm{~cm}$ no seu interior e fechada hermeticamente. Na tampa foi adaptada uma mangueira com a outra extremidade mergulhada num recipiente com água na altura de $20 \mathrm{~cm}$, para a saída de gases (PENTEADO, 2007). Os teores de Matéria seca do biofertilizante estão representados na Tabela 2.

Tabela 2. Resultado da análise do biofertilizante determinado a partir da matéria seca

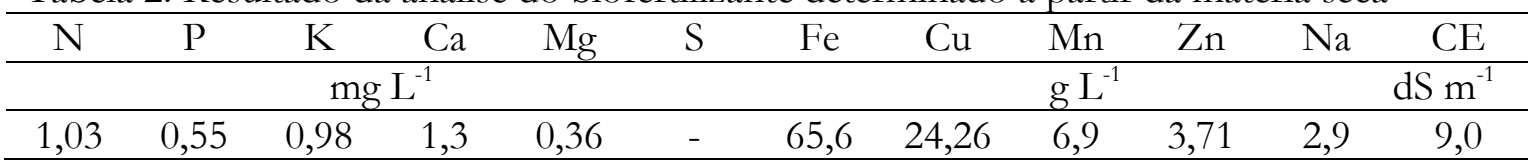

No final do experimento, aos 30 dias após a semeadura (DAS), avaliaram-se as seguintes variáveis: altura de planta, diâmetro do caule, área foliar, massa da matéria seca de raiz, parte aérea e total das plantas.

Os resultados foram submetidos à análise de variância e de regressão e, as médias comparadas pelo teste de Tukey com $\mathrm{P}<0,05$, utilizando-se o programa ASSISTAT. Na análise de regressão, as equações de regressão que melhor se ajustarem aos dados foram escolhidas com base na significância dos coeficientes de regressão ao nível de significância de $1 \%\left(^{* *}\right)$ e 5\% $\left(^{*}\right)$ pelo teste $\mathrm{F}$, e no maior coeficiente de determinação $\left(\mathrm{R}^{2}\right)$.

\section{RESULTADOS E DISCUSSÃO}

A análise de variância apresentada na tabela 3 mostrou que as diferentes concentrações de biofertilizante bovino influenciaram na altura da planta (AP), na área foliar (AF), na matéria seca da parte aérea (MSPA), da raiz (MSR) e na matéria seca total (MST). A variáveis diâmetro caulinar (DC) não foi influenciadas pelas diferentes concentrações de biofertilizante bovino em nível de significância de 1 e 5\% pelo teste $\mathrm{F}$.

Tabela 3 - Resumo da análise de variância e médias para a altura da planta (AP), diâmetro caulinar (DC), área foliar (AF), matéria seca da parte aérea (MSPA) e matéria seca total (MST) em plantas de milho em função de diferentes níveis de diluição do biofertilizante bovino. 


\begin{tabular}{lccccccc}
\hline \multirow{2}{*}{ FV } & \multicolumn{7}{c}{ QUADRADO MÉDIO } \\
\cline { 2 - 8 } & GL & AP & DC & AF & MSPA & MSR & MST \\
\hline Tratamentos & 4 & $180,384^{* *}$ & $0,865^{\text {ns }}$ & $624298,854^{* *}$ & $79,143^{* *}$ & $52,425^{* *}$ & $201,728^{* *}$ \\
Blocos & 3 & $48,052^{\text {ns }}$ & $4,203^{\text {ns }}$ & $26699,877^{\text {ns }}$ & $3,229^{\text {ns }}$ & $5,533^{\text {ns }}$ & $12,049^{\text {ns }}$ \\
Resíduo & 12 & 15,077 & 6,900 & 101783,898 & 6,110 & 2,491 & 9,905 \\
Total & 19 & - & - & - & - & - & - \\
\hline CV $(\%)$ & & 5,47 & 15,37 & 11,59 & 10,99 & 20,50 & 10,42 \\
\hline
\end{tabular}

Analisando a altura da planta em função das concentrações de biofertilizante, verificou-se que as plantas atingiram altura máxima de $82,7 \mathrm{~cm}$ quando se utilizou a concentração de $25 \%$ de participação do biofertilizante. Já a menor altura foi observada quando se aplicou a concentração de $125 \%$ de biofertilizante bovino (Figura 1).

Sousa et al. (2012) estudando o desenvolvimento inicial da cultura milho irrigado com águas de diferentes salinidades combinada com a aplicação de diferentes concentrações de biofertilizante observaram que as plantas atingiram altura máxima de 75,65 cm quando se utilizou a concentração de 39,80\% de biofertilizante. Valor esse, inferior ao encontrado nesse trabalho, usando uma concentração menor de biofertilizante.

Comportamentos semelhantes foram obtidos por Silva et al. (2008) e Campos et al. (2009) que constataram influência positiva do insumo orgânico em ambiente salino sobre o crescimento de plantas de goiabeira e mamoneira, respectivamente.

Figura 1 - Altura de plantas do milho, em função das concentrações de biofertilizante bovino no solo. Significativo ao nível de $1 \%(* *)$ pelo teste $\mathrm{F}$

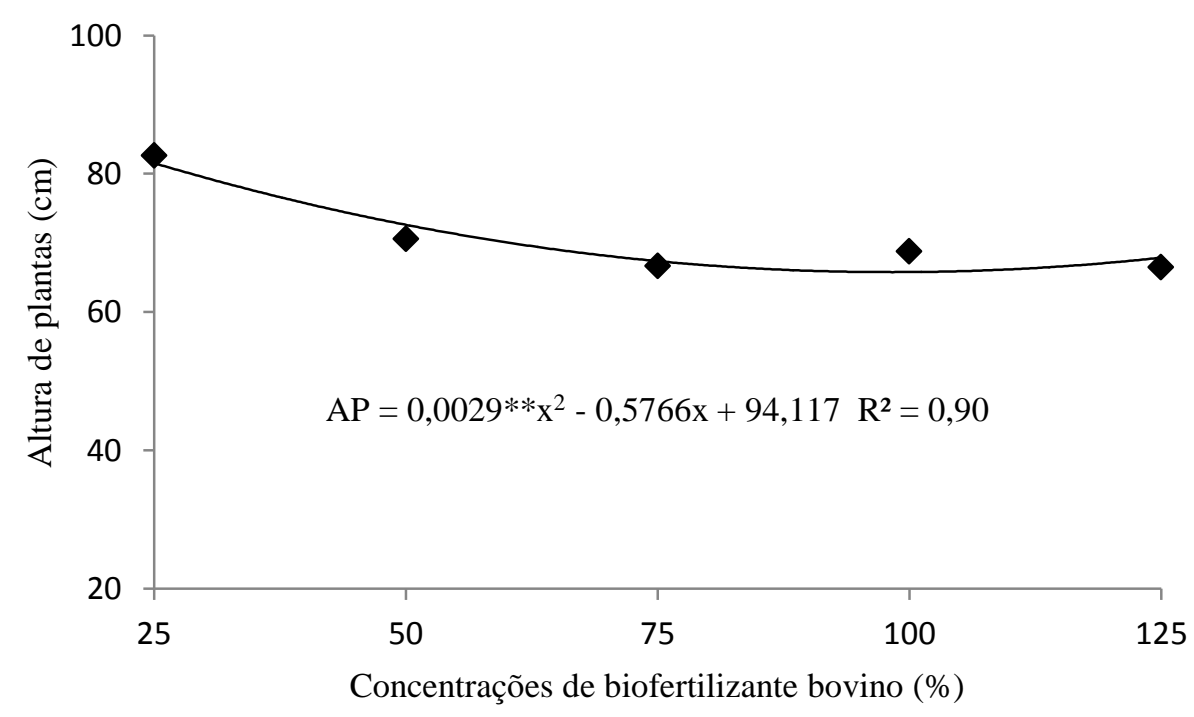

Conforme pode ser observado na figura 2, sob diferentes concentrações de biofertilizante bovino, a área foliar apresentou um comportamento quadrático, atingiu valor máximo de $3.271,24 \mathrm{~cm}^{2}$ para uma concentração de $73,7 \%$ de biofertilizante. 
Resultado semelhante ao desse estudo foram encontrados, Mesquita et al. (2010) em plantas de maracujazeiro amarelo, Cavalcante et al. (2010) em plantas de goiabeira, Silva et al. (2011) em plantas de feijão-de-corda e Sousa et al., (2012) em plantas de milho.

Acima desta concentração, observou-se uma diminuição da área foliar que se deve possivelmente, a uma maior concentração do biofertilizante que pode ter provocado uma fitoxidez, haja vista que apesar de ser um produto de base natural se faz necessário a sua utilização e aplicação na concentração correta ou o mesmo pode promover desequilíbrio fisiológico às plantas.

Mas segundo Röder et al. (2015) estudando o uso de biofertilizante na produção de mudas de repolho não encontrou relatos de redução de área foliar, em função de concentrações e de intervalos de aplicação de fontes de biofertilizantes, mas em sua pesquisa foi constato redução de área foliar com aplicação de biofertilizante.

Figura 2 - Área foliar de milho em função de concentrações de biofertilizante bovino no solo. Significativo ao nível de $5 \%\left(^{*}\right)$ pelo teste $\mathrm{F}$.

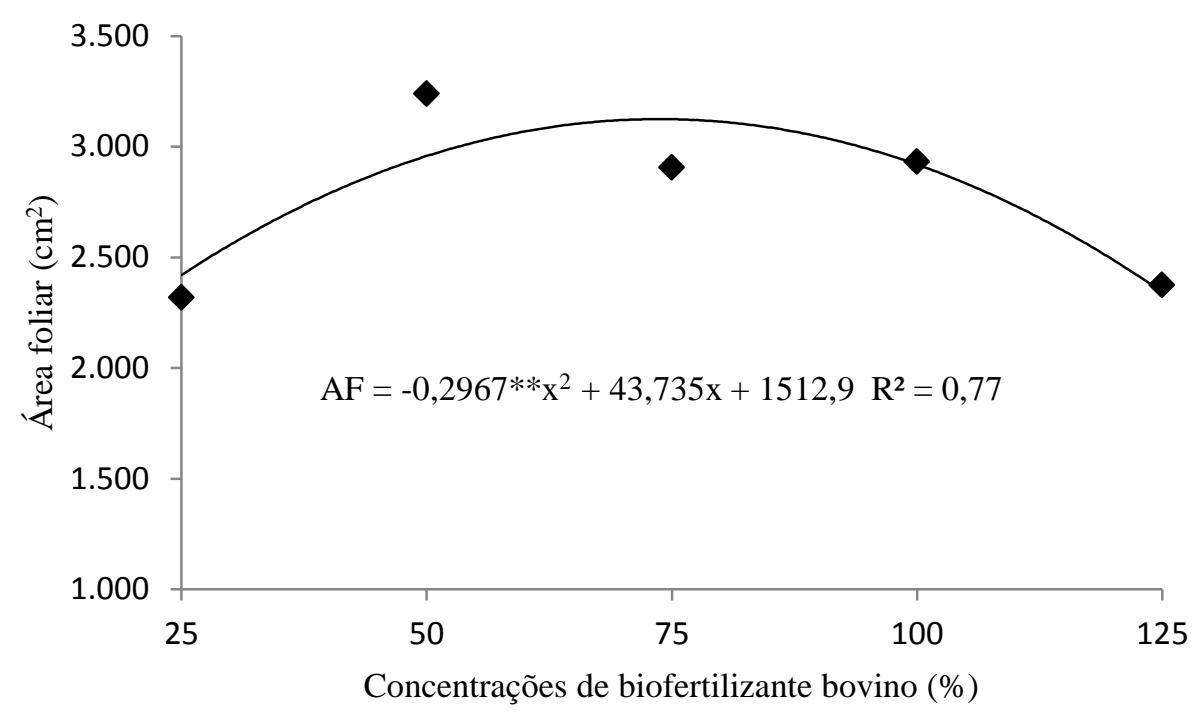

Com relação ao efeito das doses de biofertilizantes, verificou-se que o efeito da aplicação deste insumo sobre a MSPA foi variável de acordo com a concentração estudada. Para a MSPA houve resposta linear e positiva (Figura 3), obtendo-se aumento de aproximadamente 0,096 g por planta de MSPA por aumento unitário nas doses de biofertilizante.

Resultados semelhantes ao desse estudo foram encontrados por, Cavalcante et al. (2010) e Silva et al. (2011) estudando a MSPA em plantas de goiabeira e feijão-de-corda em solo com concentração de $50 \%$ de biofertilizante bovino, obtiveram uma maior MSPA em relação às plantas que não receberam o insumo orgânico.

Figura 3 - Matéria seca da parte área de milho em função das concentrações de biofertilizante bovino no solo. Significativo ao nível de $\left.1 \%{ }^{* *}\right)$ pelo teste $\mathrm{F}$ 


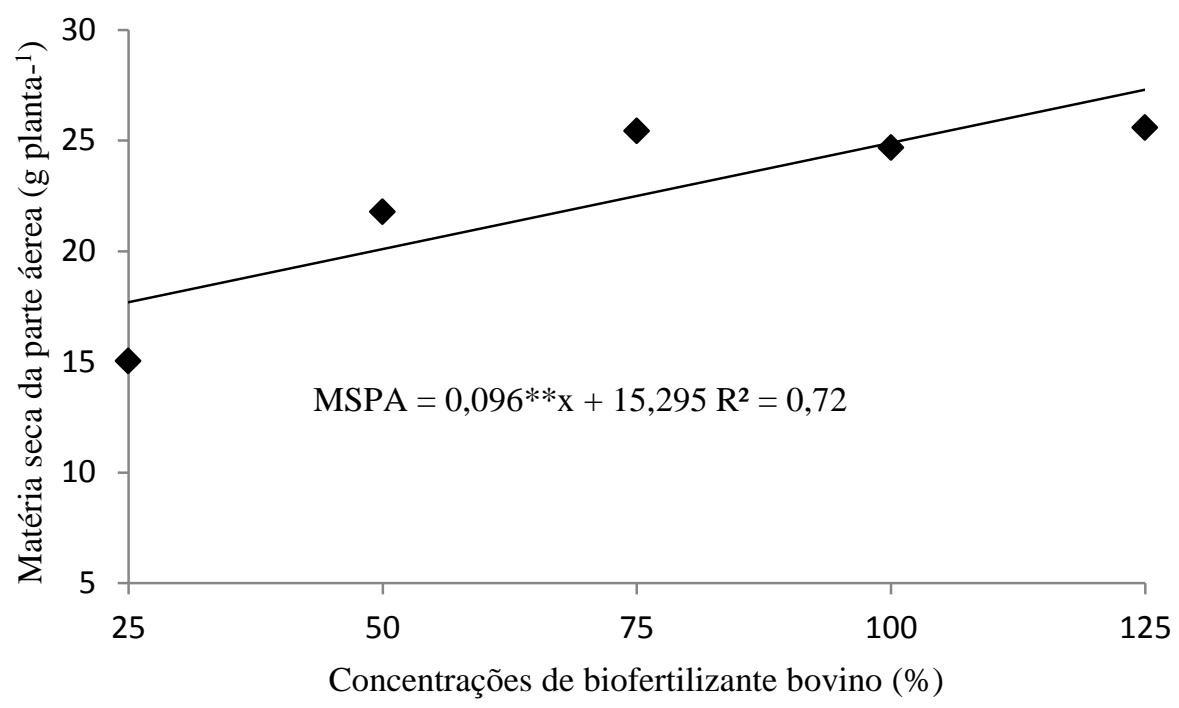

Os níveis crescentes da aplicação de biofertilizante bovino aumentaram de forma positiva a MSR em plantas de milho, sendo o modelo linear com melhor ajuste e coeficiente de determinação de $\mathrm{R}^{2}=0,61$ (Figura 6). Dessa forma é possível observar um incremento de 0,072 g por planta de MSR por aumento unitário nas doses de biofertilizante.

Possivelmente a presença de um maior teor de biofertilizante tenha contribuído para o aumento da disponibilidade de nutrientes como nitrogênio e potássio, resultando em maior crescimento da biomassa radicular. Cavalcante et al. (2010) em goiabeira e Mesquita et al. (2010) em maracujazeiro amarelo, avaliando os efeitos do estresse salino em vaso contendo biofertilizante bovino, evidenciaram uma tendência semelhante ao desse estudo sobre a MSR. Já Sousa et al. (2012) avaliando os efeitos do estresse salino em vaso contendo biofertilizante bovino na cultura do milho, evidenciaram uma tendência oposta a desse estudo sobre a MSR.

Figura 4 - Matéria seca da raiz de milho em função das concentrações de biofertilizante bovino no solo. Significativo ao nível de $1 \%\left(^{* *}\right)$ pelo teste F 


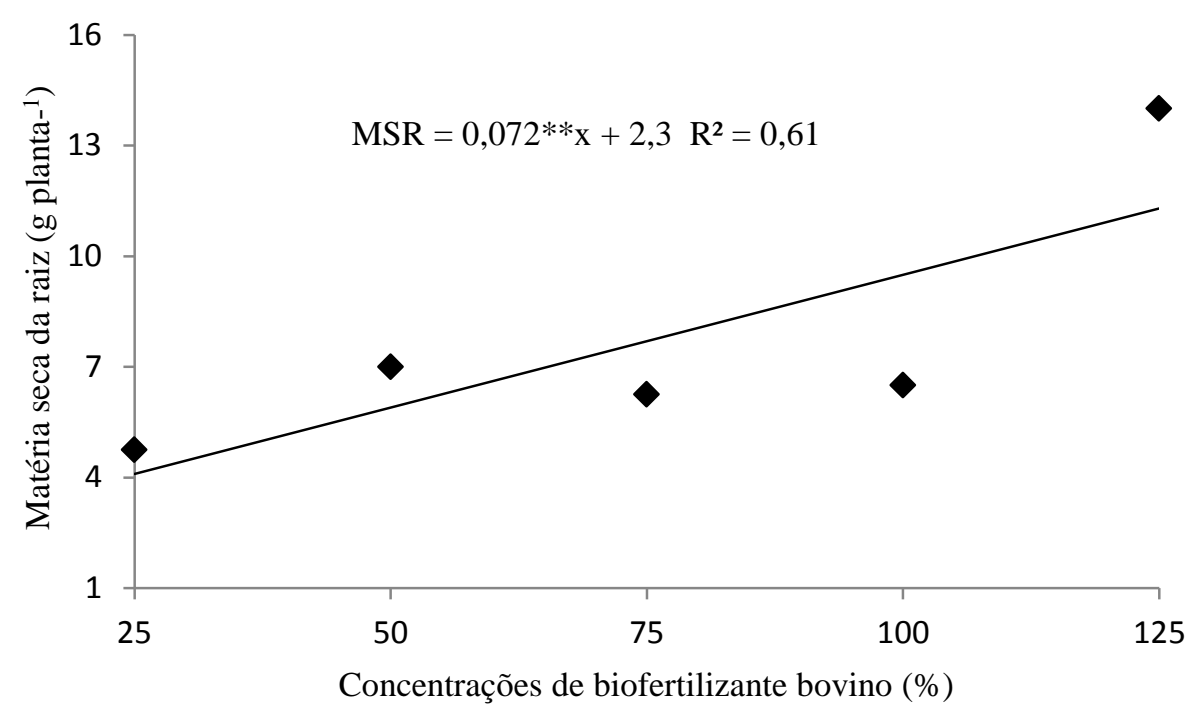

Como verificado para a matéria seca da parte aérea e da raiz, a matéria seca total das plantas de milho também foi afetada positivamente pela presença do biofertilizante bovino. De acordo com a análise de regressão verificou-se que a MST em função das concentrações de biofertilizante bovino se ajustou em um modelo linear com $\mathrm{R}^{2}$ de 0,87 (Figura 5), constatando um incremento de 0,168 g por planta de MST por aumento unitário nas doses de biofertilizante.

Pereira et al. (2015) pesquisando a cultura do feijão com diferentes concentrações de biofertilizante bovino, encontraram resultado semelhante ao desse estudo. Já Sousa et al. (2012) testando diferente concentrações salina na presença de biofertilizante encontrou um modelo quadrático para MST.

Mesquita et al. (2010) concluíram que na presença do biofertilizante bovino, nas de plantas de maracujazeiro amarelo, a MST foi significativamente superior quando comparado à ausência do insumo orgânico.

Figura 5 - Matéria seca total de milho em função das concentrações de biofertilizante bovino no solo. Significativo ao nível de 1\% (**) pelo teste F 


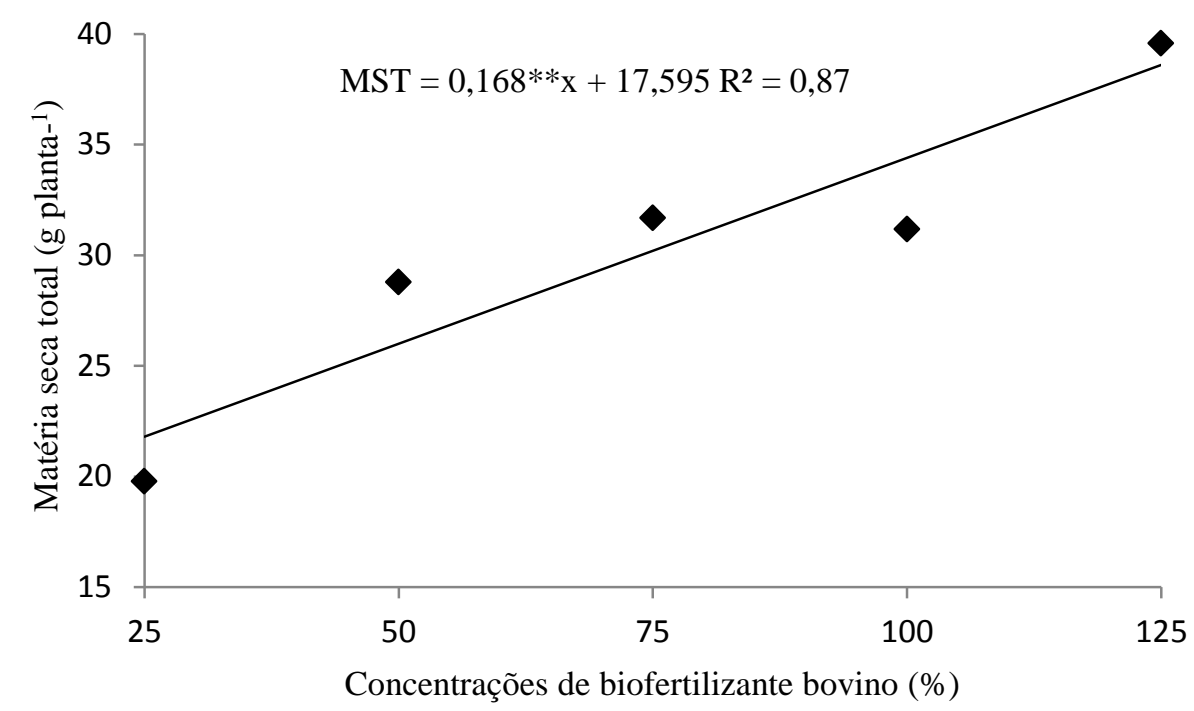

\section{CONCLUSÕES}

O incremento nas doses de fertilizante orgânico bovino proporcionou aumento da MSR, MSPA e MST.

Para a variável área foliar a concentração que promoveu um maior desenvolvimento foi a dose de $73,7 \%$ de biofertilizante.

\section{AGRADECIMENTOS}

Os autores agradecem ao Centro Vocacional Tecnológico de Produção Orgânica e Agroecológica (CVT-IFPI) pelo apoio financeiro para a realização da pesquisa e ao Instituto Federal do Piauí, Campus Campo Maior.

\section{REFERÊNCIAS}

BETTIOL, W.; TRATCH, R.; GALVÃO, J. A. H. Controle de doenças de plantas com biofertilizantes. Jaguariúma: EMATER/CNPMA, p.22, 1998.

BEZERRA, L. L.; SILVA FILHO. J. H.; FERNADES, D.; ANDRADE. R.; MADALENA, J. A.S. Avaliação da aplicação de biofertilizante na cultura do milho: crescimento e produção. Revista Verde, v.3, n.3, p. 131-139, julho/setembro, 2008.

CAMPOS, V. B. et al. Crescimento inicial da mamoneira em resposta à salinidade e biofertilizante bovino. Revista Magistra, v. 21, n. 01, p. 41-47, 2009. 
CAVALCANTE, L. F. et al. Água salina e esterco bovino líquido na formação de mudas de goiabeira cultivar paluma. Revista Brasileira de Fruticultura, v. 32, n. 01, p. 251-261, 2010.

ERTHAL, V. J.; FERREIRA, P. A.; PEREIRA, O. G.; MATOS, A. T. Características fisiológicas, nutricionais e rendimento de forrageiras fertigadas com água residuária de bovinocultura. Revista Brasileira de Engenharia Agrícola e Ambiental, v. 14, n. 5, p. 458466, 2010.

FORNASIERI FILHO, D. Manual da cultura do milho. Jaboticabal: FUNEP, 2007. 576 p.

GOMES JÚNIOR, J.; SILVA, A. J. N.; SILVA, L. L. M.; SOUZA, F. T.; SILVA, J. R. Crescimento e produtividade de tomateiros do grupo cereja em função da aplicação de biofertilizante líquido e fungo micorrízico arbuscular. Revista Brasileira de Ciências Agrárias, v. 6, n. 4, p. 627-633, 2011.

IZUMI, K. OKISHIO, Y. NAGÃO, N. NIWA, C. YAMAMOTO, S. TODA, T. Effects of particle size on anaerobic digestion of food waste. International Biodeterioration \& Biodegradation, v. 64, p. 601608, 2010.

MAGHANAKI, M. GHOBADIANA, B. NAJAfiA, G. JANZADEH GALOGAH, R. Potential of biogas production in Iran. Bioresource Technology, v. 101, p. 1153-1158, 2013.

MESQUITA, F. O. et al. Produção de mudas de maracujazeiro amarelo em substrato com biofertilizante bovino irrigado com águas salinas. Revista Agropecuária Técnica, v. 31, n. 02, p. 134-142, 2010.

OLIVEIRA, A. P.; SILVA, O. P. R.; BANDEIRA, N. V. S.; SILVA, D. F.; SILVA, J. A.; PINHEIRO, S. M. G. Rendimento de maxixe em solo arenoso em função de doses de esterco bovino e biofertilizante. Revista Brasileira de Engenharia Agrícola e Ambiental, v. 18, n. 11, p. $1130-1135,2014$.

PENTEADO, S. R. Adubação orgânica: compostos orgânicos e biofertilizantes. 2. ed. Campinas, 2007.162 p.

RÖDER, C.; MÓGOR, À, F.; SZILAGYI-ZECCHIN, V. J.; FABBRIN, E. L. S.; GEMIN, L. G.; Uso de biofertilizante na produção de mudas de repolho. Revista Ceres, Viçosa, v. 62, n.5, p. 502-505, set-out, 2015. 
SANTOS, A.C.V. dos. Biofertilizante líquido, o defensivo da natureza. Niterói: Emater-Rio, 1992. p.2045.

SANTOS, A. P. G.; VIANA, T. V. A.; SOUSA, G. G.; GOMES-DO-Ó, L. M.; AZEVEDO, B. M.; SANTOS, A. M. Produtividade e qualidade de frutos do meloeiro em função de tipos e doses de biofertilizantes. Horticultura Brasileira, v. 32, n. 4, p. 409-416, 2014.

SANTOS, M. R.; SEDIYAMA, M. A. N.; MOREIRA, M. A.; MEGGUER, C. A.; VIDIGAL, S. M. Rendimento, qualidade e absorção de nutrientes pelos frutos de abóbora em função de doses de biofertilizante. Horticultura Brasileira, v. 30, n. 1, p. 160-167, 2012.

SEVERINO, L. S.; COSTA, F. X.; BELTRÃO, N. E. M.; LUCENA, M. M.;GUIMARÃES, M. M. B.. Mineralização da torta de mamona, esterco bovino e bagaço de cana estimada pela respiração microbiana. Revista de Biologia e Ciências da Terra, Campina Grande, v. 5, n. 1, 2004.

SILVA, A. B. F. et al. Growth and yield of guava irrigated with saline water and addition of farmyard manure. Revista Brasileira de Ciências Agrárias, v. 03, n. 04, p. 354-359, 2008.

SILVA, F. L. B.; LACERDA, C. F.; SOUSA, G. G.; NEVES, A. L. R.; SILVA, G. L.; SOUSA, C. H. C. Interação entre salinidade e biofertilizante bovino na cultura do feijão-de-corda. Revista Brasileira de Engenharia Agrícola e Ambiental, v. 15, n. 4, p. 383-389, 2011.

SOUSA, G. G.; MARINHO, A.B.; ALBUQUERQUE, A. H.; VIANA, T. V. A.; AZEVEDO. B. M. Crescimento inicial do milho sob diferentes concentrações de biofertilizante bovino irrigado com águas salinas. Revista Ciência Agronômica, v. 43, n. 2, p. 237-245, abr-jun, 2012.

PEREIRA, L. B.; ARF, O.; SANTOS, N. C. .; OLIVEIRA, A. E. Z.; KOMURO, L. K. Manejo da adubação na cultura do feijão em sistema de produção orgânico. Pesquisa Agropecuária Tropical., v. 45, n. 1, p. 29-38, jan./mar. 2015

VIANA, T. V. A.; SANTOS, A. P. G.; SOUSA, G. G.; PINHEIRO NETO, L. G.; AZEVEDO, B. M.; AQUINO, B. F. Trocas gasosas e teores foliares de NPK em meloeiro adubado com biofertilizantes. Revista Brasileira de Ciências Agrárias, v. 8, n. 4, p. 595-601, 2013. 